\title{
A Successful Defect Closure After Total Excision of Seborrheic Keratoses with Atypical Clinical Presentation Using Island Pedicle Flap in an Elderly Patient
}

Eva Krishna Sutedja (D)

Rafdi Ahmed

Endang Sutedja

Rasmia Rowawi

Oki Suwarsa

Hendra Gunawan iD

Department of Dermatology and Venereology, Faculty of Medicine, Padjadjaran University - Hasan Sadikin General Hospital, Bandung, West Java, 40I6I, Indonesia

This article was published in the following Dove Press journal:

International Medical Case Reports Journal

\begin{abstract}
Seborrheic keratoses (SK) are benign skin tumor characterized by welldemarcated and skin-colored to pigmented papules, plaques, or nodules with stuck-on appearance. Typical SKs are normally treated for cosmetic reasons. However, total excision and histopathological examination have to be considered in SK with unusual properties. The island pedicle flap (IPF) is a method of flap for defect closure, especially on the cheek. It has the capability to maintain the vascularization, thus it is also suitable in the elderly. We report a case of an SK with atypical clinical presentation in a 69-year-old female, with a solitary enlarging, hyperpigmented, verrucous, and bleeding tumor. The dermoscopic examination did not show characteristic features of SK. Total excision was performed due to its clinical properties. The histopathological examination revealed hyperkeratosis, acanthosis, hyperplasia, and papillomatosis, along with intercellular pseudo-horn cyst which confirmed the diagnosis of SK. The patient underwent total excision of the skin lesion which left a primary defect. We performed IPF procedure to reconstruct the defect after total excision of the skin lesion. After a year of follow-up, no meaningful complication was detected. The final result of the procedure was satisfying due to its ability to restore the natural contour and texture match by utilizing cheek laxity, without interfering the nasolabial fold. In conclusion, IPF is an appropriate method for defect closure in an elderly patient after facial total tumor excision.
\end{abstract}

Keywords: atypical clinical manifestation, defect closure, facial tumor, island pedicle flap, seborrheic keratoses

\section{Introduction}

Seborrheic keratoses (SK) are common benign skin tumors originating from epidermal keratinocytes and usually pigmented. ${ }^{1,2}$ It is commonly identified in elderly, ${ }^{3}$ which predilections are on the head and face. The classical skin lesions are characterized by well-demarcated and skin-colored to pigmented papules, plaques, or nodules with stuck-on appearance. ${ }^{2}$ Normally, typical SKs are treated for cosmetic reasons. Various treatment modalities have been used over the years. ${ }^{3}$ However, in certain conditions in which SK has unusual clinical properties, total excision and histopathological examination have to be performed. ${ }^{2}$ Thus, appropriate surgical management is needed, which will restore aesthetic function and reconstruction, ${ }^{3}$ especially by a flap. ${ }^{4}$
Correspondence: Hendra Gunawan Department of Dermatology and Venereology, Faculty of Medicine, Padjadjaran University - Hasan Sadikin General Hospital, Jl. Pasteur No. 38, Bandung, West Java, 4016I, Indonesia TellFax +62 222032426 ext. 3449 Email h.gunawan2016@unpad.ac.id 
The flap is a technique for reconstructing soft tissue defects due to trauma or surgical excision. ${ }^{5}$ It was first introduced by Sushruta Samhita in 700 BC, as a reconstruction technique on the tip of the nose by using skin from the cheek. ${ }^{4,6}$ In 1898, Monk introduced island pedicle flap (IPF), a defect closure technique for the excised epithelioma. ${ }^{4}$ It reconstructs small to moderate defect after skin excision on the upper lip, eyebrows, forehead, lower nose, cheeks, and postauricular parts. ${ }^{7}$ This method can facilitate wound closure and minimize the risk of complications that usually occur in other flap techniques and skin grafts.

The aim of this case report was to show a successful IPF for defect closure after total excision of an SK with atypical clinical presentation in a 69 -year-old female.

\section{Case Report}

A 69-year-old female, married, high school graduated, housewife, presented with an asymptomatic, enlarging, hyperpigmented, easily bleed verrucous tumor on the left cheek for six months. The skin lesion started as an asymptomatic hyperpigmented papule on the left cheek since two years before the consultation. One year later, the skin became enlarged, gradually darker, and bled easily. The patient tried to treat the skin lesion with a cream bought at the pharmacy, but it just relieved the bleeding. The patient denied previous history of chronic disease and malignancy, trauma and radiation exposure former to the tumor, contact with certain substances, or similar complaints in her family. There was history of chronic sun exposure without using a hat nor sunscreen. There was no history of smoking, alcohol consumption, nor long-time medication.
Clinical examination of the skin lesion revealed a painless hyperpigmented and verrucous tumor on the left cheek, lateral to the nasolabial fold, with the diameter size $1 \mathrm{~cm}$. There was no distortion of the adjacent structure. A non-tender rubbery mass fixed to the underlying structure in the stuck-on appearance was identified on palpation (Figure 1). The dermoscopic examination did not show characteristic features of SK. Histopathological examination revealed hyperkeratosis, acanthosis, hyperplasia, and papillomatosis, along with intercellular pseudohorn cyst, which supported the diagnosis of SK (Figure 2).

We performed total excision of the tumor under tumescent anesthesia. After determining the tumor and skin marking (Figure 3A), surgical excision was performed around the lesion line to loosen the tumor from the underlying structure. An approximately $1 \mathrm{~cm}$ diameter clean wound base was left after the tumor excised (Figure 3B), which was called the primary defect. We performed the IPF to achieve optimal cosmetic result. The method was initiated by semi triangular-shaped incision along the relaxed skin tension line (RSTL) on the inferolateral aspect of the primary defect (Figure 3C). The incised cutaneous tissue was further undermined below the superficial fat layer. This left a semi-triangular shaped loose tissue, which was called secondary defect. Therefore, the secondary defect was further advanced medio-superiorly to cover the primary defect (Figure 3D), and fixed with interrupted sutures (Figure 3E-F). Through observations over time, we could see the initial skin lesion (Figure $4 \mathrm{~A})$, the trap-dooring which was observed on the 7th day of the follow-up (Figure 4B), and the result of the

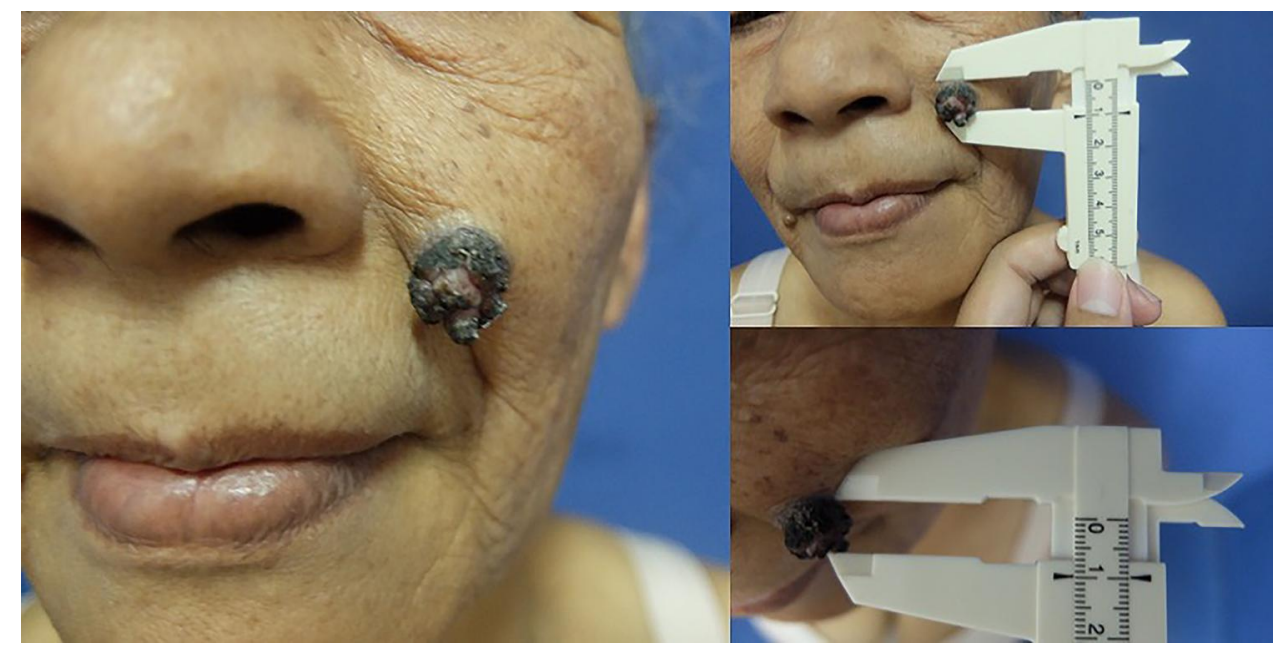

Figure I Clinical manifestation of the case. The skin lesion of the patient, a solitary tumor next to the nasolabial fold. 

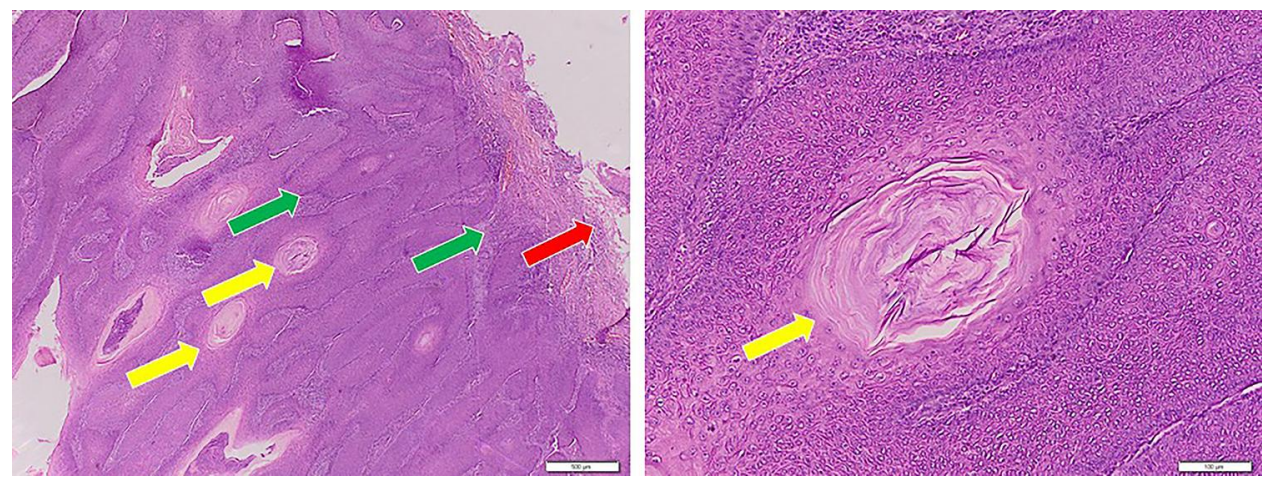

Figure 2 Histopathological appearance of the case. The histopathological features of the skin lesion, hyperkeratosis (red arrow), acanthosis, hyperplasia, and papillomatosis (green arrow), along with intercellular pseudo-horn cyst (yellow arrow), which support the diagnosis of SK.

Abbreviation: SK, seborrheic keratoses.

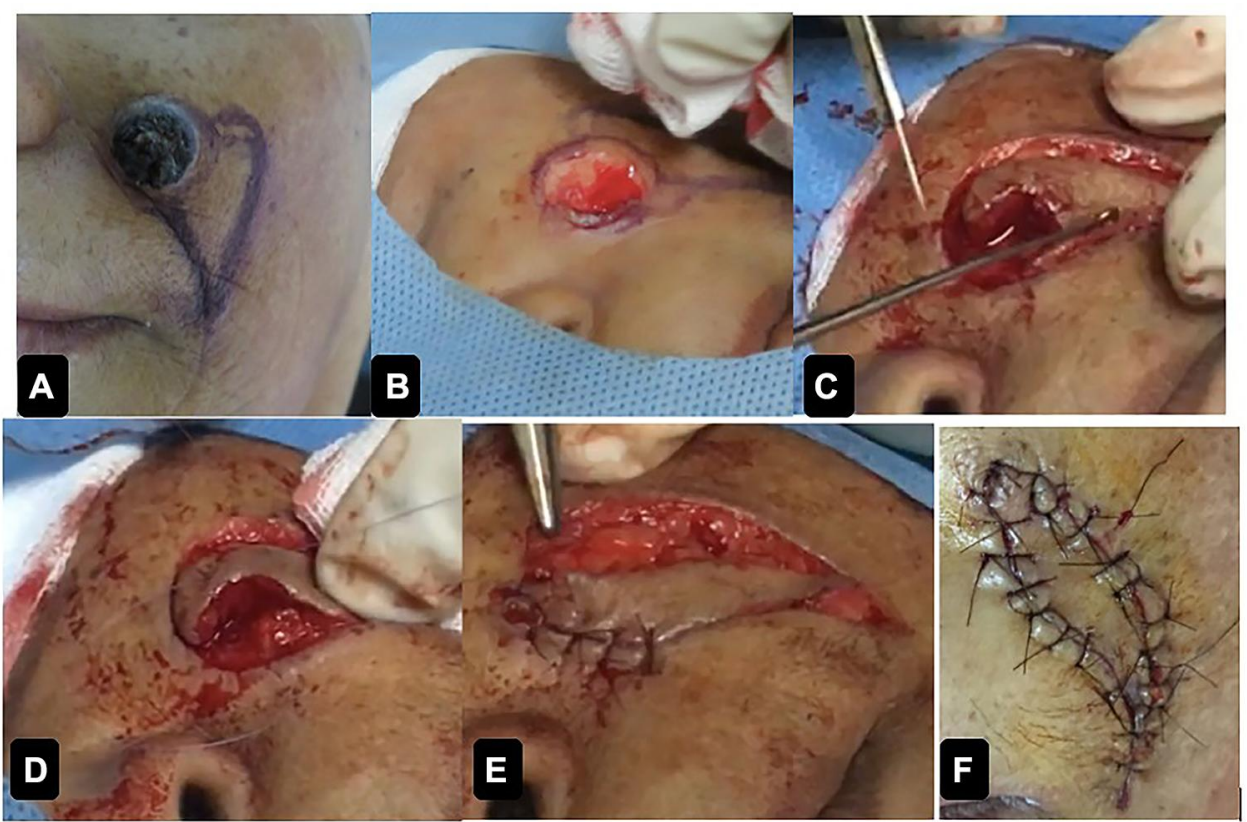

Figure 3 Excision and defect closure steps. (A) The tumor and skin marking for IPF; (B) Total excision of the tumor; (C) The initial step of IPF, making incision of secondary defect; (D) Advancing the flap to the primary defect; (E) Suturing the flap; (F) The final step of the IPF procedure.

Abbreviations: SK, seborrheic keratoses.

reduction after stripe application (Figure 4C). After one year of observation, the final result revealed similar contour with the adjacent tissue, without interfering adjacent structure (Figure 4D).

\section{Discussion}

Seborrheic keratoses are skin lesions considered as tumor in elderly. It is commonly found in people older than 50 years. ${ }^{1}$ Its predilections are commonly found in sunexposed areas, especially on the head and face. ${ }^{3}$ Normally, a typical SK can be diagnosed clinically by well-demarcated and skin-colored to pigmented, papules, plaques or nodules, ${ }^{2}$ with stuck-on appearance. ${ }^{2,3}$ The hallmark of pathologic findings is hyperkeratosis, acanthosis, and papillomatosis. The typical SK is normally treated for cosmetic reasons due to the undesirable lesion, and the principle of the treatment is to destroy the lesion with various therapeutic modalities, such as cryotherapy, curettage, electrodessication, laser, electrocautery, shave excision, and total excision ${ }^{3}$ with linear closure or flap. ${ }^{4}$

Unusual presentation of SK can be indicated by changes in size, enlargement, gradual darkening, chronic inflammation, focal pigmentation, bleeding, irregular shape, and hyperpigmentation. This condition resembles 

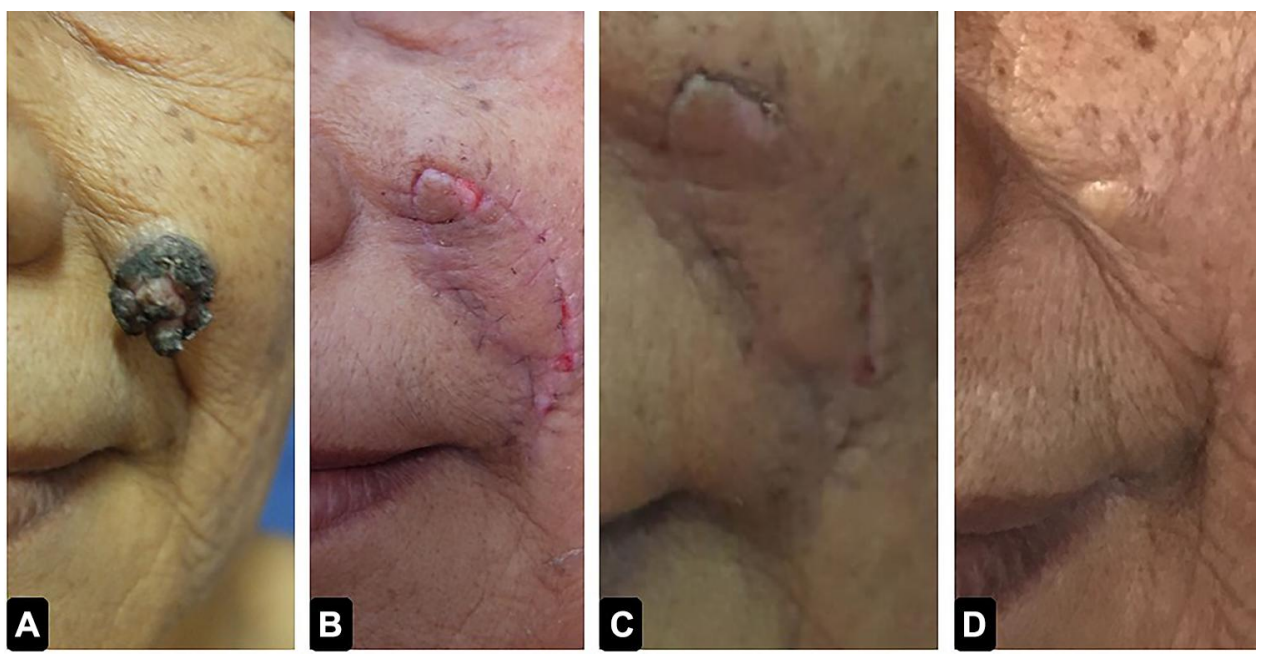

Figure 4 Clinical manifestation and evolution of the tissue before and after treatment. (A) The initial lesion; (B) The complication of the procedure: trap-dooring which happened on the 7th day of the follow up; (C) The trap-dooring after managed by stripes application; (D) The final result of the flap after I year of follow up, similar contour of the skin and undisturbed nasolabial fold.

cutaneous malignancies, including basal cell carcinoma, squamous cell carcinoma, or verrucous melanoma. ${ }^{2}$ In these circumstances, critical evaluation and total excision of the skin lesion are recommended. ${ }^{3,8}$ However, restoring natural contours and facial boundaries by returning symmetrical shapes, proportions, and balance, with minimal scarring after facial tumors excision is essential, ${ }^{9}$ since the treatment of facial SK is done for cosmetic reasons. ${ }^{8}$

In this report, the patient was a 69-year-old elderly female, with enlarging and bleeding skin lesion on the cheek, with stuck-on appearance. We decided to perform total excision in this patient due to the atypical clinical properties, with the histopathological examination result supporting the diagnosis of SK. We chose IPF for defect closure, to restore natural contour, symmetrical shape, and proportion in this elderly patient's face.

The flap is a technique of soft tissue defect reconstruction, ${ }^{5}$ used in large primary defect and high tension area, when linear closure cannot achieve optimal function and aesthetic aspects of the result. ${ }^{10}$ Flap restores the natural contour, texture similarity, and natural function, ${ }^{11}$ by a structure consisting of the skin, subcutaneous tissue, and vascular supply transferred from the donor site to the recipient site. ${ }^{6}$ The IPF is one of flap technique which has an adequate vascular supply, ${ }^{4}$ thus it correlated with high survival rates and low morbidity. ${ }^{7}$ This technique maintains the vascular supply by vascular pedicle which remains connected to the donor site. To maintain vascularization, undermining and mobilizing flaps must be done at or below the superficial layer of fat. ${ }^{10}$ IPF was considered to be the appropriate method, since skin blood flow is reduced by about $40 \%$ on average in the elderly. ${ }^{12}$ Moreover, this method is suitable for defect closure on the cheek, which utilizes the flexibility of the lower aspect of the cheeks. ${ }^{13}$

We decided flap as defect closure method in this patient, because the excision of the lesion left a primary defect, and also the nasolabial fold as the adjacent structure of the lesion. Therefore, it requires natural contour restoration and tension reduction, which does not interfere with the natural function. Since the patient was elderly and possibly have decreased vascularity, IPF was considered to be an appropriate method due to its capability to maintain vascularity. Therefore, it has high survival rate and low morbidity.

The trap-dooring and substantial scar are common complications of this method. ${ }^{4,7}$ Trap-dooring is often found 1-2 weeks after IPF procedures. The trap-dooring responds to the manual massage or intralesional corticosteroid injection. ${ }^{7}$ Unfortunately, trap-dooring was observed on the 7th day of the follow-up, and was managed by stripe application. After a year of follow-up, there were no meaningful complications observed. The patient was satisfied with the final result, and the goal of this method, which include contour restoration and natural function were achieved.

\section{Conclusion}

An IPF is an appropriate method for defect closure in an elderly patient after facial total tumor excision. This 
procedure has advantages for facial defect closure, because it can minimize the risk of complications.

\section{Abbreviations}

SK, seborrheic keratoses; IPF, island pedicle flap; RSTL, relaxed skin tension line.

\section{Ethical Approval}

This study was conducted in compliance with the Declaration of Helsinki, Good Clinical Practices, local regulatory requirements, and was approved by the Medical Ethics Committee of Hasan Sadikin General Hospital Bandung (approval number: LB.02.01/X.6.5/ 324/2020).

\section{Consent for Publication}

The patient signed informed consent forms. She also signed forms giving consent for the use of case details and images for publication and for scientific purposes.

\section{Acknowledgment}

Authors would like to thank all staff of the Dermatology and Venereology Department, Faculty of Medicine Universitas Padjadjaran - Hasan Sadikin General Hospital Bandung.

\section{Author Contributions}

All authors made a significant contribution to the work reported, whether that is in the conception, study design, execution, acquisition of data, analysis and interpretation, or in all these areas; took part in drafting, revising or critically reviewing the article; gave final approval of the version to be published; have agreed on the journal to which the article has been submitted; and agree to be accountable for all aspects of the work.

\section{Funding}

The authors declare that this study has received no financial support.

\section{Disclosure}

The authors report no conflicts of interest in this work.

\section{References}

1. Gill D, Dorevitch A, Marks R. The prevalence of seborrheic keratoses in people aged 15-30 years: is the term senile keratosis redundant? Arch Dermatol. 2000;136:759-762. doi:10.1001/ archderm.136.6.759

2. Chen TY, Morison AO, Cockerell CJ. Cutaneous malignancies simulating seborrheic keratosis: an underappreciated phenomenon? J Cutan Pathol. 2017;44:9. doi:10.1111/cup.12975

3. Thomas VD, Snavely NR, Lee KK, Swanson NA. Benign epithelial tumors, hamartomas, and hyperplasia. In: Wolff K, Goldsmith LA, Katz SI, et al., editors. Fitzpatrick Dermatology in General Medicine. 8th edition ed. New York: McGraw Hill; 2012:p.1319-36.

4. Braun M, Cook J. The island pedicle flap. Dermatol Surg. 2005;31:995-1005. doi:10.1111/j.1524-4725.2005.31824

5. Rahpeyma A, Khajehahmadi S. The place of nasolabial flap in orofacial reconstruction: a review. Ann Med Surg (Lond). 2016; p.79-87. doi:10.1016/j.amsu.2016.11.008

6. Wysong A, Higgins S. Basic principles in flap reconstruction. In: Rohrer TE, Cook JL, Kaufman AJ, editors. Flaps and Grafts in Dermatologic Surgery. 2nd ed. Philadelphia: Elsevier; 2018:p.16-31.

7. Bader RS, Johnson D. Island pedicle flap: a useful tool for the repair of forehead defects. Cosm Dermatol. 2009;22(2):p.96-8.

8. Noiles K, Vender R. Are all seborrheic.keratoses benign? Review of the typical lesion and its variants. J Cutan Med Surg. 2008;12 (5):203-210. doi:10.2310/7750.2008.07096

9. Wayne F, Larrabee Jr. Design of local skin flaps. Otolaryngol Clin North Am. 1999;23:899-923.

10. Sheehan JM, Kingsley M, Rohrer TE. Excisional surgery and repair, flaps, and grafts. In: Wolff K, Goldsmith LA, Katz SI, et al., editors. Fitzpatrick Dermatology in General Medicine. 8th ed. New York: McGraw Hill; 2012:p.2930-44.

11. Hidayatullah O, Asif M, Tahir M, Aslam M. J Ayub Med Coll Abbottabad. 2005;17:3.

12. Bentov I, Reed MJ. The effect of aging on the cutaneous microvasculature. Microvasc Res. 2015;100:25-31. doi:10.1016/j. mvr.2015.04.004

13. Leonhardt JM, Lawrence N. Back to basics: the subcutaneous island pedicle flap. Dermatol Surg. 2004;30:1587-1590. doi:10.1111/j.15244725.2004.30572.x

\section{Publish your work in this journal}

The International Medical Case Reports Journal is an international, peer-reviewed open-access journal publishing original case reports from all medical specialties. Previously unpublished medical posters are also accepted relating to any area of clinical or preclinical science. Submissions should not normally exceed 2,000 words or 4 published pages including figures, diagrams and references. The manuscript management system is completely online and includes a very quick and fair peer-review system, which is all easy to use. Visit http://www.dovepress.com/testimonials.php to read real quotes from published authors. 